\title{
XXIII. The moist-combustion process: some reactions of alkaline permanganate of potash
}

\section{J. Alfred Wanklyn \& W.J. Cooper}

To cite this article: J. Alfred Wanklyn \& W.J. Cooper (1879) XXIII. The moist-combustion process: some reactions of alkaline permanganate of potash , Philosophical Magazine Series 5, 7:41, 138-139, DOI: $10.1080 / 14786447908639576$

To link to this article: http://dx.doi.org/10.1080/14786447908639576

曲 Published online: 13 May 2009.

Submit your article to this journal $[\pi$

Џ Article views: 2

Q View related articles 
pendicularly on the first plane of the prism, the angle $i$ being then evidently zero.

Of course the angle of the prism can also be determined with this instrument; and it is not necessary to alter any thing in its arrangement or to move the prism. We have only to clamp the telescope in a position of about $90^{\circ}$ to the collimator, and then to observe the reflected image alternately on both faces of the prism.

In order to be able to use the instrument for other purposes, both telescope and collimator can be shifted parallel to their axes and be fixed by the screws $\mathrm{OO}^{\prime}$. If the instrument is to be used as a spectroscope, one may put conveniently before the objectives of telescope and collimator prisms with direct vision.

XXIII. The Moist-Combustion Process: some Reactions of Alkaline Permanganate of Potash. By J. AlfRed WANKLYN and W. J. COOPER*.

FOLLOWING up our investigations (the results of which were communicated in the June Number of this Journal, and in the Chemical Section of the British Association at the Dublin Meeting last year), we have now to announce that we have overcome one of the difficulties which stood in the way of giving to our process absolute generality of application to all organic substances.

It will be remembered that, starting with the organic substance in aqueous solution, we showed that permanganate of potash and excess of alkali burnt down the organic substance to the state of carbonates, oxalates, and water; and we proposed to render the solution acid, and so, as was well known, would burn down the oxalates to carbonates. At the Dublin Meeting we announced that although this answers very well in many cases, yet in certain classes of cases acetates appeared among the products of oxidation; and when once produced, acetates resisted further oxidation.

We have now managed to oxidize the acetates, by the simple process of using considerable excess of permanganate and raising the temperature some 60 or 80 degrees above the boiling-point of water. Under these conditions acetate of potash yields carbonate of potash, and apparently no oxalate whatever.

There is a difficulty, however, attendant on the use of these

* Communicated by the Authors. 
high temperatures; and on this occasion we wish to explain this difficulty and how it has been overcome.

The difficulty arises from the fact that, at temperatures very little above $100^{\circ} \mathrm{C}$, a mixture of pure permanganate of potash and caustic potash evolves oxygen gas. This fact we have very carefully ascertained, both by noting the diminution in oxidizing-power which the solution shows after being heated to $180^{\circ}$ in the oil-bath, and by actually collecting and measuring the oxygen gas which was evolved during the heating in the oil-bath. The gas is evolved very freely at temperatures even below $140^{\circ} \mathrm{O}$; and the numerical results accord very fairly with this equation:-

$$
2\left(\mathrm{KMnO}_{4}\right)+2(\mathrm{KHO})=2\left(\mathrm{~K}_{2} \mathrm{MnO}_{4}\right)+\mathrm{H}_{2} \mathrm{O}+\mathrm{O} .
$$

Here, as will be observed, the permanganate of potash is represented as losing one fifth of its active oxygen, and yielding manganate of potash.

It has long been known that at very elevated temperatures, at temperatures bordering on low redness, permanganate of potash parts with oxygen and forms manganate of potashthat, in point of fact, at these elevated temperatures manganate, and not permanganate, is the stable form of combination; but we believe this easy evolution of oxygen at temperatures a little above the boiling-point of water is quite a novelty. For the moist-combustion process it would be a very uncomfortable novelty if we were unable to stop the evolution of the gas by a convenient device, since the alkaline permanganate would cease to keep a trustworthy record of the consumption of oxygen during the process.

We have, however, to add that we can stop the evolution in a most convenient manner. We mix some hydrated binoxide of manganese with the permanganate and alkali; and then there is no evolution of oxygen. Why this addition should be effective is obvious; and the chemist will have no difficulty in understanding that the necessity of having to make such a condition does not damage our process.

We have to record, as an interesting reaction, the behaviour of green oxide of chromium with strongly alkaline solution of permanganate of potash. It acts very readily, and yields chromate of potash and hydrated binoxide of manganese ; this takes place at temperatures even below the boiling-point of water. We are following up this experiment, and hope to make new and rare metallic acids. 